\title{
Assessment of Knowledge, Attitude and Utilization of Emergency Contraception Among Women of Reproductive Age in Arsi Zone, Ethiopia
}

Getu Teshome Negussie ( $\sim$ g_teshome86@yahoo.com )

Arsi University College of Health Sciences https://orcid.org/0000-0001-7991-5470

Aman Jima

Arsi University College of Health Sciences

Alemu Shiferaw

Arsi University

\section{Research}

Keywords: Emergency contraceptives, Unmarried women, Arsi, Ethiopia

Posted Date: November 9th, 2021

DOl: https://doi.org/10.21203/rs.3.rs-968690/v1

License: (1) (i) This work is licensed under a Creative Commons Attribution 4.0 International License.

Read Full License 


\section{Abstract}

Background: Unintended pregnancies, pregnancies that occur within short intervals as well as unsafe abortion could be avoided by using contraceptives. Therefore: assessment of emergency contraceptives among unmarried women is importance because of high rates of unintended sexual intercourse leading to unwanted pregnancies as well as unsafe abortion.

Methods: A cross-sectional community based household survey was conducted among 965 women chosen by systematic random sampling at Arsi zone. Descriptive statistics was presented with text and frequency tables. Both bivariable and multivariable logistic regression analysis was carried out by Epi Info version 5.3.1 and exported to SPSS version 21. The association was also presented using odds ratios and $95 \%$ confidence levels. P-value of $<0.05$ is used to declare the significance of association between variables.

Results: From the total respondent participated in the study, $373(38.7 \%), 61.8 \%$, and $11.2 \%$ of the total unmarried women had awareness, attitude and used emergency contraception respectively. Age, educational status, occupation, having experience of sexual intercourse and having discussion on reproductive health are significantly associated with awareness of emergency contraception.

Conclusions: There is high level of knowledge, but low utilization of emergency contraceptives among unmarried women. Therefore, there is a need to emphasize on increasing awareness and accessibly as an option with other contraceptive method to all unmarried women in the study area.

\section{Background}

Emergency contraception (EC) is defined as contraceptive methods that reduce the chance of pregnancy following unprotected sexual intercourse $\left({ }^{1}\right.$.) They are intended for use after sexual intercourse when no contraception is used, when a regular contraceptive method does not work properly, or if a woman is sexually assaulted ${ }^{2}$.) A woman can take ECPs within 72 hours or more after unprotected intercourse to reduce her risk of becoming pregnant. They contain a higher dose of the same active ingredients that regular birth control pills contain. Recent research suggests the pills are also effective, if taken within 120 hours of unprotected sexual intercourse $(1,2$.) Progestin pills are more effective and are associated with fewer side effects than combined emergency contraceptive pills $\left({ }^{3}\right.$.) Another form of emergency contraception is the insertion of a copper Intra Uterine Device (IUD) by a trained healthcare professional $(1,4$.

Emergency contraception adds an important option for helping sexually active unmarried to avoid unintended pregnancy. Many unmarried women are at high risk of unintended pregnancy; they have limited knowledge of contraception and generally lack access to services or do not feel comfortable using these services $\left({ }^{2}\right.$.) 
Nowadays, ECs have become more available in many developing countries. However, limited awareness and knowledge, as well as limited access, have hindered unmarried and young women in learning about and using ECs $\left({ }^{2}\right.$.) A review of the evidence shows that adolescents' restricted access to emergency contraception is due to their lack of awareness of ECs, barriers to their use of family planning clinics, including embarrassment, lack of familiarity with the clinics, inconvenient clinic hours; fear of a pelvic examination and provider attitudes $\left({ }^{5}\right.$.)

According to Ethiopian Demographic Survey (EDHS) 2011, 27 \% of Ethiopian women of reproductive age (15-49 years) have never been married. Among those never been married the highest proportions $(77 \%)$ were between the age of 15 and 19 years. But the median age at first intercourse for the women age 1549 were 17.1 years. The steadily decreasing age of menarche and increasing age of marriage have created a widening window of time for premarital sexual intercourse which may result in unwanted or unintended pregnancies $\left({ }^{2}\right.$.) Unintended pregnancies and pregnancies that occur within short intervals and abortions pose serious health risks to young women $\left({ }^{6-10}\right.$.) As a consequence, most of unintended pregnancies end with induced abortion which contributes for high maternal mortality $\left({ }^{11}\right.$.)

Global and regional estimates of annual incidence of unsafe abortion and associated mortality in 2003 shows, the incidence rate of 14 per 1000 women aged 15-44 years which accounts for $13 \%$ of all maternal deaths worldwide. In eastern Africa the incidence estimated to be 39 per 1000 and accounts for $17 \%$ of all maternal deaths $\left({ }^{11}\right.$.) By preventing pregnancy before it happens, ECs help reduce the number of unintended pregnancies, as well as the number of abortions and associated maternal mortality $\left({ }^{12,13}\right.$.)

Despite increase in promotional activities of modern contraceptive methods among unmarried women the utilization is relatively low. In Ethiopia current use of contraception is lower (18.7\%) among all women of reproductive age group $\left({ }^{14,15}\right.$.) In addition, in all reproductive age group only $52.3 \%$ of sexually active unmarried women are currently using any modern contraceptive methods $\left({ }^{15}\right.$.) As it has been discussed ECs helps in reducing the risk of unintended pregnancy, its consequence unsafe abortion as well as associated maternal mortality among unmarried women which are at risk. Different institutional based studies have shown that the knowledge and utilization in relation to emergency contraception are limited among women $\left({ }^{16-37}\right.$.)

\section{Methods}

Cross-sectional community based study was conducted at Arsi Zone in Oromia National Regional State about 175 kilo meters to southeast of Addis Ababa, Capital city of Ethiopia. According to the projection from 2007 census, total population of the zone estimated to be 3,202,689. Arsi Zone is currently organized in 25 administrative structures called 'woreda'. The health service coverage is $88 \%$. The proportion of women of reproductive age group in the region is $22.1 \%$, total fertility rate of $5.6\left({ }^{15}\right.$.)

The sample sizes were determined using single proportion formula. Assuming the proportion of unmarried women who aware of emergency contraception to be $50 \%$ since there is no study conducted at 
the community level, $5 \%$ marginal error, $95 \%$ confidence interval and $10 \%$ non-response rate were added. Then multiplied by 2 for design effect due to multistage sampling and total sample size was 998 .

A total of 10 rural 'kebeles' and 5 urban 'kebeles' were selected from five 'woredas'. Based on the total population of selected woredas the sample sizes were allocated proportional to population size. Similarly, the sample sizes were distributed to kebeles according to their proportion. Then using systematic sampling the study subject was interviewed at household level using structured questionnaire. Data were collected by female nurses experienced in data collection, and checked for completeness and consistency on daily basis by the supervisors. Data were cleaned and entered to the computer using Epi Info version 5.3.1 and exported to SPSS (Statistical Package for the Social Sciences) version 21 statistical software and analysis were performed. Descriptive statistics (mean and standard deviation) was used and results were present with text and frequency tables. Both bivariable and multivariable logistic regression analysis was carried out to identify factors associated with awareness of EC among the study subject. At bivariable analysis level to select best predictor variables and those variables that are going to show significant association at a p-value of less than 0.20 was entered into multivariable analysis. The association of variables was also presented using odds ratios relative to the reference category and $95 \%$ confidence levels. P-value of $<0.05$ is used to see the significance of association between dependent and independent variables.

\section{Results}

Complete responses were obtained from a total of 965 respondents yielding a response rate of $97.7 \%$. The age of the respondent ranged from 15 to 35 years with mean age of 19.5 and standard deviation of 3.65 years. Above half of them 555(57.5\%) were between the age of 15 and 19 years. Regarding residency, $586(60.7 \%)$ of the respondent were rural resident. Three hundred eighty one $(39.5 \%)$ of the respondents were orthodox Christian followers (Table 1). 
Table 1

Socio demographic characteristics of unmarried women of reproductive age in Arsi Zone, January 2018, Ethiopia

\begin{tabular}{|c|c|c|}
\hline Variables & Frequency & Percent \\
\hline Age $15-19$ & 555 & 57.5 \\
\hline $20-24$ & 307 & 31.8 \\
\hline $25-29$ & 87 & 9.0 \\
\hline $30+$ & 16 & 1.7 \\
\hline Residence Rural & 586 & 60.7 \\
\hline Urban & 379 & 39.3 \\
\hline Religion Orthodox & 381 & 39.5 \\
\hline Muslim & 369 & 38.2 \\
\hline Protestant & 192 & 19.9 \\
\hline Catholic & 23 & 2.4 \\
\hline Ethnic Group Oromo & 548 & 56.8 \\
\hline Amhara & 272 & 28.2 \\
\hline Tgray & 38 & 3.9 \\
\hline Gurage & 87 & 9 \\
\hline Others & 20 & 2.1 \\
\hline Educational Status No Education & 37 & 3.8 \\
\hline Primary Education & 268 & 27.8 \\
\hline Secondary Education & 467 & 48.4 \\
\hline Higher Education & 193 & 20 \\
\hline Occupation Government Employee & 53 & 5.5 \\
\hline Private Business & 78 & 8.1 \\
\hline Private Employee & 141 & 14.6 \\
\hline Student & 626 & 64.9 \\
\hline Others & 67 & 6.9 \\
\hline
\end{tabular}


Age at menarche ranged from 10 to 18 years with a mean age of 14.1 and standard deviation of 1.2 year. About 458(47.5\%) of the respondents had knowledge of fertile days between two menstrual periods when a woman is more likely to become pregnant if she has sexual intercourse (second and third weeks of the menstrual cycle). Out of the total 965 respondents, 344(35.6\%) have had sexual intercourse in their life time.

Among those who had sexual experience $(n=344), 124(36 \%)$ of the respondents had been pregnant, out of this $96(77.4 \%)$ of pregnancy were unwanted and $79(63.7 \%)$ ended in induced abortion. Out of 79 induced abortion $45(57 \%)$ were performed by untrained personnel. Five hundred thirty nine $(55.9 \%)$ of the respondents discuss about reproductive health issue particularly about conception and contraception with at least someone else.

Three hundred seventy three $(38.7 \%)$ of the total sampled unmarried women had ever heard about emergency contraception. Three hundred fifty five (95.2\%) of those ever heard of EC mentioned oral pills only and the reminder (4.8\%) mentioned oral pill and IUD as method of emergency contraception. The major sources of information were from television /radio 168(45\%). Of those who have heard about pills as an emergency contraceptive method, $300(80.4 \%)$ identified the correct time of administration of pills after unintended/unprotected sexual intercourse. When asked about how EC works, 358(96\%) of those aware of EC mentioned that EC prevents from getting pregnant (Table 2). 
Table 2

Knowledge of emergency contraception among unmarried women of reproductive age in Arsi Zone, January 2018, Ethiopia.

\begin{tabular}{|c|c|c|c|}
\hline Characteristics & Response & Frequency & Percent \\
\hline \multirow[t]{2}{*}{ Ever heard of EC $(n=965)$} & No & 592 & 61.3 \\
\hline & Yes & 373 & 38.7 \\
\hline \multirow[t]{2}{*}{ Types of EC ever heard $(n=373)$} & Oral pill only & 355 & 95.2 \\
\hline & Oral pill and IUD & 18 & 4.8 \\
\hline \multirow{5}{*}{$\begin{array}{l}\text { Source of information about EC }(n= \\
\text { 373) }\end{array}$} & TV/ Radio & 168 & 45 \\
\hline & Health worker & 99 & 26.5 \\
\hline & Family/friends & 56 & 15 \\
\hline & Formal education & 30 & 8 \\
\hline & Health institution & 20 & 5.5 \\
\hline \multirow{5}{*}{$\begin{array}{l}\text { When to take ECP after unprotected } \\
\text { sex }(n=373)\end{array}$} & Within 72 hrs after sex & 300 & 80.4 \\
\hline & Within 24 hrs after sex & 36 & 9.7 \\
\hline & Immediately after sex & 21 & 5.6 \\
\hline & Within 5 days & 6 & 1.6 \\
\hline & $\begin{array}{l}\text { Others (one wk, after missed period, } \\
\text { don't know) }\end{array}$ & 10 & 2.7 \\
\hline \multirow[t]{3}{*}{ How EC works $(n=373)$} & Prevent pregnancy occurrence & 358 & 96 \\
\hline & Don't Know & 13 & 3.5 \\
\hline & Induce abortion & 2 & 0.5 \\
\hline
\end{tabular}

About 596(61.8\%) of the study participant women had positive attitude towards making EC available to all women who need it. The remainder mentioned to raped victims $201(20.8 \%)$, to young female $135(14 \%)$, and to married women only $33(3.4 \%)$. The majority $(79 \%)$ of the respondent have an intention to use EC in the future if the need arises and the rest has no intention to use EC in the future. Those who have an intention to use EC when the need arises prefer to get service from public health institution 525(68.9), from private pharmacy $165(21.7 \%)$, and from private clinic $72(9.4 \%)$ (Table 3 ). 
Table 3

Attitude of emergency contraception among unmarried women of reproductive age in Arsi Zone, January 2018, Ethiopia.

\begin{tabular}{|c|c|c|c|}
\hline Characteristics & Response & Frequency & Percent \\
\hline \multirow[t]{4}{*}{ To whom EC should be given $(n=965)$} & To all women who need it & 596 & 61.8 \\
\hline & To raped victims & 201 & 20.8 \\
\hline & To young female & 135 & 14 \\
\hline & To married women only & 33 & 3.4 \\
\hline Intention to use EC in future if need arise & Yes & 762 & 79.0 \\
\hline$(n=965)$ & No & 203 & 21.0 \\
\hline \multirow[t]{2}{*}{ Ever used EC $(n=373)$} & No & 331 & 88.8 \\
\hline & Yes & 42 & 11.2 \\
\hline
\end{tabular}

In multivariate analysis, age, educational status and occupation had statistically significant association with the awareness of emergency contraception. Women aged 20 years and above were more likely to have knowledge about emergency contraception than those below 20 years of age AOR $=2.06(95 \% \mathrm{Cl}$ : $1.52,2.81$ ). Awareness of EC was higher among the respondent with secondary [AOR 4.07 (95\% Cl: 2.81 , 5.91)] and above education [AOR $=6.33(95 \% \mathrm{Cl}: 4.04,9.90)]$ when compared to those with primary education and no education. Government employees and those engaged in private business more likely to have awareness of EC than private employees and others (house maid, daily laborers) AOR $=1.83$ ( $95 \%$ $\mathrm{Cl}: 1.10,3.06)$, and students were 1.70 times more likely to have knowledge of EC than private employees AOR=1.70(95\% Cl: 1.14, 2.53) (Table 4).

Those who ever had sexual intercourse were more likely to have knowledge of EC than those who never had sexual intercourse (AOR=3.08 (95\% Cl: 2.24, 4.22). The EC awareness was higher among those who had discussion of Reproductive Health $(\mathrm{RH})$ issue than never had discussion (AOR=2.95 (95\% Cl: 2.08, 4.17) (Table 4). 
Table 4

Relationship between Variables and awareness of emergency contraception among unmarried women of reproductive age in Arsi Zone, January 2018, Ethiopia.

\begin{tabular}{|c|c|c|c|c|}
\hline \multirow[t]{2}{*}{ Variables } & \multicolumn{2}{|c|}{ Awareness of EC } & \multirow[t]{2}{*}{ COR (Cl: 95\%) } & \multirow[t]{2}{*}{ AOR (Cl: 95\%) } \\
\hline & Yes & No & & \\
\hline \multicolumn{5}{|l|}{ Age } \\
\hline $15-19$ & 165 & 390 & 1.00 & 1.00 \\
\hline $20+$ & 208 & 202 & $2.43(1.86,3.17)$ & $2.06(1.52,2.81)^{*}$ \\
\hline \multicolumn{5}{|l|}{ Educational Status } \\
\hline No and Primary Education & 46 & 259 & 1.00 & 1.00 \\
\hline Secondary Education & 208 & 259 & $4.52(3.14,6.49)$ & $4.07(2.81,2.91)^{\star}$ \\
\hline Higher Education & 119 & 74 & $9.05(5.90,13.88$ & $6.33(4.04,9.90) *$ \\
\hline \multicolumn{5}{|l|}{ Occupation } \\
\hline Student & 251 & 375 & $2.06(1.44,2.93)$ & $1.70(1.14,2.53)^{\star}$ \\
\hline Government Employee \& private Business & 71 & 60 & $3.64(2.28,5.81)$ & $1.83(1.10,3.06)^{*}$ \\
\hline Private employee and others & 51 & 157 & 1.00 & 1.00 \\
\hline \multicolumn{5}{|l|}{ Religion } \\
\hline Orthodox & 223 & 158 & 1.00 & 1.00 \\
\hline Muslim & 249 & 120 & $0.68(0.50,0.91)$ & $0.73(0.42,1.27)$ \\
\hline Protestant and Catholic & 120 & 95 & $1.1(0.79,1.56)$ & $1.34(0.79,2.26)$ \\
\hline \multicolumn{5}{|l|}{ Ethinic Group } \\
\hline Oromo & 332 & 216 & 1.00 & 1.00 \\
\hline Amhara & 168 & 104 & $0.95(0.70,1.28)$ & $0.91(0.56,1.49)$ \\
\hline Gurage & 64 & 23 & $1.64(0.95,2.83)$ & $0.86(0.48,1.53)$ \\
\hline Tigre and Others & 28 & 30 & $0.55(0.33,0.91)$ & $0.43(0.40,1.32)$ \\
\hline \multicolumn{5}{|l|}{ Ever had sexual intercourse } \\
\hline No & 459 & 162 & 1.00 & 1.00 \\
\hline Yes & 133 & 211 & $4.41(3.33,5.85)$ & $3.08(2.24,4.22)^{*}$ \\
\hline \multicolumn{5}{|l|}{ Discuss RH issues } \\
\hline No & 349 & 75 & 1.00 & 1.00 \\
\hline
\end{tabular}




\begin{tabular}{|lccll|}
\hline Variables & Awareness of EC & COR (Cl: 95\%) & AOR (Cl: 95\%) \\
\hline yes & 243 & 298 & $5.70(4.22,7.71)$ & $2.95(2.08,4.17)^{\star}$ \\
\hline Ever used any contraceptive method & & & & \\
\hline No & 336 & 207 & 1.00 & 1.00 \\
\hline Yes & 89 & 166 & $3.02(2.22,4.12)$ & $1.39(0.61,3.19)$ \\
\hline
\end{tabular}

* Statistically significant

\section{Discussions}

Less than fifty percent of the total respondents mentioned that a woman likely become pregnant within 23 weeks of the menstrual cycle if they had sexual intercourse. The finding was in agreement with a study conducted among University students in Mekele $\left({ }^{33}\right.$.) Out of the total 965 respondents, $344(35.6 \%)$ have had sexual intercourse in their life time. The prevalence of sexual relationship was lower than the results of University students in Kampala, Nigerian undergraduate students where $42 \%$ and $43 \%$ of the students had sexual experience respectively $(24,25$.)The low sexual relationship prevalence could be the respondents might not express their real history because they considered that premarital sex is not socially accepted norm. The result of this study was higher than the findings among female university students in Addis Ababa, Mekele, Deberemarkos and Adama where $19.5 \%, 17.3 \%, 26.4 \%$ and $29.4 \%$ had ever had sexual experience respectively $(22,28,31,33$.)

In this study, about $83.3 \%$ of the total respondent had ever heard about modern contraceptive methods. This result shows lower knowledge of modern contraceptive methods than studies done among university students in Debremarkos (91.9\%), Adama (95.2\%) and Mekele (93\%) $\left({ }^{27,}{ }^{28,33}\right.$.) This difference could be due to difference in socio-economic differences of the study participant especially educational level. Furthermore, among the respondent who had ever heard about modern contraceptive methods only $32 \%$ reported ever used any modern contraceptive methods and the result of this study was higher than the studies done among under graduate students in Debremarkos (24\%), Adama (10.7\%) \&Mekele $(10.3 \%)(27,28,33$. $)$ This difference could be due to deference prevalence of sexual relationship in these universities and the community.

From the total study participants, three hundred seventy three (38.7 \%) had ever heard of emergency contraception. This result lower than the study done among female University Students in Addis Ababa (43.5\%), Debremarkos(71.1\%), Adama (46.8\%), Mekele University (44.7\%), Kampala University (45\%) and Nigerian undergraduate students $(58 \%)(24,25,27,28,31,33$.) This great discrepancy might be due to the socio demographic difference of the respondents such as the age, occupation, educational status and marital status of the respondents.

In this study $61.8 \%$ of the total respondent had positive attitude towards making EC available to all women who need it and $79 \%$ have an intention to use EC in the future when the need arises. Respondents 
in this study had better attitude towards EC when compared to study in Addis Ababa University students where $52.6 \%$ had positive attitude towards making EC available to all women who need it and $63 \%$ of the students had an intention to use EC in the future $\left({ }^{30,31}\right.$.) On other hand, the finding of this study is lower than the studies among university students in Mekele and Adama where $75.5 \%$ and $63 \%$ of the respondent had positive attitude towards emergency contraception $(28,33$.) The difference in attitude could be due to difference socio- demographic characteristics such as educational status and occupation.

Awareness of EC remained higher for the respondent aged 20 years and above compared to their younger with AOR $2.06(1.52,2.81$.) This result had similarity with study done in Deberemarkos, Adama and Mekele University, $(27,28$, and 33 .) Educational status were significantly associated with awareness of EC in this study i.e. those who had secondary education or above had better awareness than those with no education and primary education. In others studies this had similar findings that is as the level of education increases awareness also higher $(27,28833$.)

Government employees, private business owners and students had better awareness than those classified as private employees and others. But this is not shown in other studies $(27,28 \& 33$.) The significance seen in this study could be due deference in socio-demographic characteristics among study subjects.

Eve had sexual intercourse, ever had discussion about RH issues and pervious knowledge of contraceptive methods use remains highly significant to increase awareness of emergency contraception. This finding is in agreement with the result of the studies in Debremarkos, Adama and Mekele University students $(27,28 \& 33$.)

\section{Conclusions}

The study has shown that the knowledge of modern contraceptive was higher but the utilization is relatively low. This is an indication of significant risk of unwanted pregnancy and induced abortion among the sexually active unmarried women. With regard to emergency contraception the study shows low awareness and better level of positive attitude towards emergency contraception. Therefore, there is a need to develop strategies in order to raise awareness of the community about emergency contraceptive as an option with other contraceptive method. Further research of providers and male partners and follow-up stud of all females on emergency contraception provision and utilization could be important to strengthen the service.

\section{Abbreviations}

AOR: Adjusted Odds Ratio

COR: Crude Odds Ratio 
EC: Emergency Contraception

EDHS: Ethiopian Demographic Survey

IUD: Intra Uterine Device

$\mathrm{RH}$ : Reproductive Health

SPSS: Statistical Package for the Social Sciences

\section{Declarations}

\section{Ethical Approval and consent to participate}

Ethical clearance was obtained from research review board of Arsi University and Arsi Zonal Health Department. Verbal informed consent was also obtained from the respondents.

\section{Consent for Publication}

Not Applicable

\section{Availability of Data and Material}

The data generated or analyzed during this study is available from the corresponding author on reasonable request.

\section{Competing Interests}

The authors declare that they have no competing interests

\section{Funding}

This study did not receive any specific grant.

\section{Authors' Contributions}

All stated authors: GTN, AJ and AS are involved in the study from the inception to design, developed the tool, coordinated and supervised data collection, analyzed and interpreted statistical analysis, and drafted manuscript. All authors read and approved the final manuscript

\section{Acknowledgements}

The authors express their gratitude to Arsi University, college of health sciences, study participants, and data collectors who provided us the necessary information in the study area.

\section{References}


1. WHO. Family Planning: A Global Handbook for Providers. 2007.

2. FHI. Adolescents and Emergency Contraceptive Pills in Developing Countries FHI Working Paper Series No. WP05-01.

3. Population Council. Emergency Contraceptive Pills, South East Asia Regional Training Manual. 2005.

4. WHO. Medical eligibility criteria for contraceptive use - 4th ed, 2009.

5. International Consortium for Emergency Contraception (ICEC). Expanding Global Access to Emergency Contraception. Seattle, WA: ICEC, 2000. Available at: http://www.cecinfo.org/html/resdownloadable-mtrls.htm\#materials

6. Federal Democratic Republic of Ethiopia Population Census Commission. Summary and Statistical Report of the 2007 Population and Housing Census Results. December 2008, Addis Ababa.

7. WHO, UNICEF, UNFPA, and the World Bank. Maternal mortality in 2005: estimates.

8. WHO. Beyond the numbers: reviewing maternal deaths and complications to make pregnancy safer. 2004.

9. Moore Z. Trends in Youth Reproductive Health in Ethiopia. 2000 and 2005.

10. UNICEF. The State of the World's Children. 2011.

11. WHO. Unsafe abortion: global and regional estimates of incidence of unsafe abortion and associated mortality in 2003. 5th ed, 2007.

12. Senbeto E. Prevalence and associated risk factors of Induced Abortion in northwest Ethiopia. Ethiop. J. Health Dev. 2005; 19 (1): 37-44.

13. PATH. Resources for Emergency Contraceptive Pill Programming: A Toolkit, 2004.

14. Govindasamy P. Youth Reproductive Health in Ethiopia. Calverton, Maryland: ORC Macro, 2002.

15. Central Statistical Agency [Ethiopia] and ICF International. Ethiopia Demographic and Health Survey 2011. Addis Ababa, Ethiopia and Calverton, Maryland, USA. 2012.

16. Latin American Consortium for Emergency Contraception. Emergency Contraception Advocacy In Latin America And The Caribbean, 2005.

17. IPPF. Every Woman's Right: Recommendations for Improving Knowledge and Access to Emergency Contraception. 2006.

18. Susie B. Who Is Using Emergency Contraception? Awareness and Use of Emergency Contraception Among California Women and Teens, Women's Health. Issues 18 (2008) 360-368.

19. Gurung N. Knowledge of Family Planning and Emergency Contraception in a Rural Female Population. Journal of GMC-Nepal. sept.2009; 2(3).

20. Lee. Women's knowledge of and attitudes towards emergency contraception in Hong Kong: questionnaire survey. HKMJ. December 1999; 5(4).

21. Puri, S . Emergency contraception in Women of Slum in Northern India. Journal of Family and Reproductive Health. 2009; 3(3). 
22. Akani C. Emergency Contraception: Knowledge and Perception Of Female Undergraduates in the Niger Delta Of Nigeria. Ghana Medical Journal. Number 2, 2008; 42.

23. Nworah 0 . Knowledge, attitude and practice of emergency contraception among students in tertiary schools in Anambra State Southeast Nigeria, International Journal of Medicine and Medical Sciences . January, 2010;2(1): 001-004.

24. Michael E. "Knowledge and Perception on Emergency Contraception among Female Nigerian Undergraduates". International Family Planning Perspectives.2003; 29(2): 84-87.

25. Byamugusha J. Emergency contraception and fertility awareness among university students in Kampala, Uganda. Afr Health Sci . 2006;6(4):194-200.

26. Belfour $\mathrm{O}$ and Fauster K. Knowledge and Practices of Emergency Contraception among Ghanaian Women. African Journal of Reproductive Health. June 2011; 15(2): 147.

27. Tassema M. and Bayu H. Knowledge, Attitude and Practice on Emergency Contraception and Associated Factors among Female Students of Debre-Markos University, Debre-Markos Town, East Gojam Zone, North West Ethiopia. Global Journal of Medical Research: E Gynecology and Obstetrics. $2015 ; 15(1)$.

28. Tilahun D, Assefa T, and Belachew T. Knowledge, Attitude and Practice of Emergency Contraceptives Among Adama University Female Students. Ethiop J Health Sci. 2010 ;20(3): 195-202.

29. Abera H, Mokonnen M, and Jara D. Knowledge, Attitude, Utilization of Emergency Contraceptive and Associated Factors among Female Students of DebreMarkos Higher Institutions, Northwest Ethiopia, 2014. Fam Med MedSci Res. 2014. 4: 149. doi: 10.4172/2327-4972.1000149

30. Ahmed F. Assessing knowledge, attitude, and practice of emergency contraception: a cross- sectional study among Ethiopian undergraduate female students. BMC Public Health. 2012; 12:110.

31. Tamire W and Enqueselassie F. Knowledge, attitude, and practice on emergency contraceptives among female university students in Addis Ababa, Ethiopia. Ethiop. J. Health Dev. 2007;21:(2):111116.

32. Tajure, N. Knowledge, Attitude and Practice of Emergency Contraception among Graduating Female Students of Jimma University, South West Ethiopia. Ethiop J Health Sci. 2010; 20(2).

33. G/yohannes E. Assessment of Knowledge, Attitude and Utilization of Emergency Contraception among Mekelle University Female Undergraduate Students. 2009.

34. Worku A. Emergency Contraceptives: Knowledge, Attitudes and Practices among Female College Students in Arba Minch, Ethiopia, Harar Bulletin of Health Sciences

35. Dessalegn B. An Assessment of Knowledge, Attitude and Practice of Emergency Contraception among women seeking post abortion care services in Addis Ababa. 2006.

36. Dinku E. Assessment of the Barriers to Emergency Contraception use among Antenatal care clients of Addis Ababa Health Centers. 2007.

37. Mengistu S. Assessment of level of awareness and utilization of Emergency Contraception among college female students, in Oromia regional state, Arisi zone, Asella town, south east Ethiopia. 2007. 